\title{
PS Dreyer: Bakens op die pad van die wetenskap
}

\author{
AJ Antonites
}

\begin{abstract}
PS Dreyer: Beacons on the path of science

Professor PS Dreyer is an academic who has shown insight and vision into several problems of the human sciences since 1951. He has identified problems, but also contributed solutions to them. In this respect his philosophy on causality and freedom is of utmost importance. The same applies to his investigations into the relationship history-Christianity as well as the unity of sciences and how the concepts scientific, unscientic and nonscientific are related to one another. His contribution to the understanding of Greek philosophy should be of significance for time to come. Two milestones could be distinguished: Dreyer's particular solution to the problem of the criterion on truth, viz meaningfulness and his notion of the knowledge of values in ethics by valuation in contradistinction to knowledge through feeling, reason and will.
\end{abstract}

\section{INLEIDEND: DIE MENS - PS DREYER}

Petrus Secundus Dreyer is gebore op 23-11-21 op Pietersburg. Eers het hulle op Pietersburg en toe Pietersburg-omgewing gewoon. Hierna word sy vader verplaas na Noordwes-Kaapland. Die gesin woon agtereenvolgens op Pofadder, Kenhardt en Williston waar sy vader oorlede is. Hy slaag standerd 8 op Kenhardt. Vervolgens gaan hy na die Hoër Jongenskool te Stellenbosch (tans die Paul Roos Gimnasium) waar hy standerd 10 aflê aan die einde van 1937.

Hierna gaan hy na die Universiteit van Pretoria. Hier behaal hy die BA-graad (einde 1940), BD (einde 1943), MA-Wysbegeerte (1945) en die D Phil-eksamen (1946). In Januarie 1948 het hy begin studeer in Nederland, en wel aan die Rijksuniversiteit van Groningen. Hier lê hy sy Drs Phil af en keer in 1950 terug na Suid-Afrika. In 1951 behaal hy die D Phil aan die Universiteit van Pretoria met 'n proefskrif oor die Antropologie van Ludwig Feuerbach. In 1958 behaal hy die DD met 'n proefskrif oor die Geskiedenisbeskouing van Arnold Toynbee.

Tydens sy verblyf in Europa het hy ook gestudeer onder die beroemde wysgeer, prof Helmut Plessner, wat 'n sterk invloed op sy 
denke gehad het. Hy woon ook lesings by van die groot filosoof, Martin Heidegger en groot teoloog, Karl Barth. Sy toegewydheid in sy studies kom onder andere aan die lig deurdat hy eers gou die Deense taal aangeleer het om sodoende ' $n$ bepaalde werk van Kierkegaard in sy oorspronklike vorm te kan lees! Sy lewenservaring in sowel die Noordwes-Kaap as Europa was nie net vir homself van betekenis nie, maar ook vir sy studente en almal wat hom geken het.

Teen die begin van 1952 word hy aangestel as tydelike lektor in die Departement Wysbegeerte aan die Universiteit van Pretoria. Aan die begin van 1953 het dit 'n voltydse pos geword en het die Dreyer-gesin na Pretoria verhuis. Daarna is hy agtereenvolgens aangestel as senior lektor, mede-professor en professor en hoof van die Departement Wysbegeerte.

Toe hy sy BD voltooi het, was hy te jonk om as predikant beroep te word. (Hy moes minstens 23 jaar oud wees.) Om dié rede het hy vir 'n jaar as hulpprediker van ds S Vermooten in die Gemeente Pretoria gedien. Aan die einde van 1944 het hy 'n beroep aanvaar na Pretoria. Aan die einde van 1945 aanvaar hy 'n beroep na Witbank waar hy tot die einde van 1947, toe hy na Nederland vertrek het, gebly het. By sy terugkeer in 1950 was hy as predikant in Potchefstroom-Noord tot einde 1952 werksaam.

In Desember 1945 is hy getroud met Maria Levina Akkerhuis. Uit die huwelik is gebore:

$\begin{array}{ll}\text { David Johannes } & \text { - 'n bourekenaar in Pretoria; } \\ \text { Elfriede } & \text { - getroud met André Pretorius, ingenieur in Pre- } \\ & \text { toria; }\end{array}$

Willem Akkerhuis - predikant in Thabazimbi.

Daar is tans vyf kleinkinders.

Na sy aanstelling aan die Universiteit van Pretoria het hy as pastorale hulp gedien vir korter en langer periodes in die Hervormde Gemeentes Pretoria-Oos, Sundra, Primrose, Edenvale, Bergsig, Elandspoort, Brixton, Greylingstad, Magaliesmoot, Poort en Heidelberg (Tvl).

\section{DREYER - DIE AKADEMIKUS}

Reeds van vroeg af in sy akademiese loopbaan het Dreyer groot belangstelling gehad in die geskiedenis as sodanig, sowel as in die wetenskap van die geskiedenis. Min het hy besef dat hierdie belangstelling en 
daaruit voortspruitende navorsing en studie nog van groot betekenis sou wees vir die geskiedeniswetenskap, en daarmee die geesteswetenskappe in die algemeen. Dieselfde sou 'n mens kon sê van sy belangstelling in die Griekse Wysbegeerte en die Etiek.

Van meet af het hy sekere sake baie netjies en deurdringend ontleed. Hierin het hy probleme raakgesien wat geblyk het korrek te wees. So het hy byvoorbeeld in 1951 tydens sy rede voor die Eerste Kongres vir Wysbegeerte in Kaapstad, aangetoon dat daar iets groots skeel by die Geesteswetenskappe. Daar is naamlik ' $n$ fundamentele gebrek aan eenheid van doel, metode en aanwending wat jy nie by die natuurwetenskappe aantref nie. Dis juis hierdie sake waarop die wysbegeerte sowel as geesteswetenskappe in die jare hierna hulle aandag grootliks toegespits het. Tewens, Dreyer self het as akademikus hieraan deelgeneem en nie ' $n$ klein bydrae gelewer nie.

Hy toon ook visie en insig met dieselfde rede deur die vraag te vra of die mens self vooruitgegaan het te midde van veral natuurwetenskaplike vooruitgang. Hiermee saam het hy die vraag gevra of daar nie weer geroep sal word na die vroeër so geminagte geesteswetenskappe om 'n weg te wys en 'n uitkoms te bied nie. Nou in 1986: Is dit nie juis wat die afgelope dekades al hoe meer gebeur het nie?

In dieselfde jaar 1951 (dit was deurgaans sy standpunt) stel hy dat die wysbegeerte hom nooit volkome van die verskillende geesteswetenskappe kan losmaak nie. Doen die wysbegeerte dit wel, sal hy sy kontak met die praktyk verloor en naderhand bloedarmoedig word. Omgekeerd kan die vakwetenskappe nie hulle kontak met die wysbegeerte verloor nie, omdat hulle steeds om verskillende prinsipiële kwessies struikel en dit moet uitmaak. Daarom is daar 'n gedurige wisselwerking tussen die wysbegeerte as sodanig en die verskillende vakwetenskappe.

As mens nou let op die hedendaagse wetenskapfilosofiese debat, dan blyk ook hierdie insig raak te wees. Afgesien hiervan het Dreyer hierdie siening van homself waarheid gemaak in sy opus magnus, Inleiding in die filosofie van die geskiedenis. Dit kom eweneens na vore in talle van sy ander publikasies en artikels.

Dreyer se oopvlekking van die wesenlike by sulke kwessies soos vryheid en kousaliteit sal nog lank meespreek in die wetenskap. Sy onderskeid en uitwerk van kousaliteit enersyds en grond andersyds, is van die grootste belang. Oor kousaliteit en rede, asook oor vryheid, is al baie gediskusseer. Dreyer se aanpak en konstruksie van hierdie saak adem egter 'n helderheid en oorspronklikheid wat ongekend is. Dit 
toon hoe lank en deurdringend hy oor hierdie aangeleentheid besin het. Dit blyk vanaf ' $n$ lesing gehou voor die Suid-Afrikaanse Kongres vir Wysbegeerte in 1955 tot met sy werk, Inleiding in die filosofie van die geskiedenis, in 1974.

Die verhouding tussen geskiedenis en Christendom het Dreyer baie geïnteresseer. Hiermee saam gaan die problematiek van historisme. Hy het vasgestel dat die historiese as deel van die geskiedsfilosofiese problematiek veel eerder val onder ' $n$ bepaalde lewensopvatlike benadering. Wesenlik tot die historiese is die individuele, en wesenlik tot laasgenoemde is verandering en kontingensie. In 1958, tydens 'n voordrag by die Vierde Suid-Afrikaanse Kongres vir Filosofie, het hy aangetoon hoedat die historisme staan teenoor die naturalisme. Sy filosofering en filosofie (hy onderskei tussen die twee) met betrekking tot die sin van die geskiedenis, waarde-werklikheid-waarheid geniet vandag veel waardering in wetenskaplike kringe. Sy heldere uiteensetting van geskiedenis by die wetenskap van die geskiedenis enersyds en geskiedenis by die Christelike geloof en teologie, is iets wat nog steeds met groot vrug gelees kan word deur sowel filosowe as teoloë. Ingrypend is sy denke oor die onlosmaaklikheid van geskiedenis en die Christelike geloof, maar in afgrensing van die historisme. Tekenend hiervan is byvoorbeeld sy onderskeid tussen en denke rondom Jesus Christus, Seun van God aan die een kant en Alexander die Grote, die seun van Filippus van Macedonië: Kan altwee histories en onties benader word en hoe? - het hy gevra. Geen benadering van hierdie aard is ooit deur enigiemand anders so gedoen nie.

'n Lewendige maar moeilike probleem in die wetenskapsfilosofie was die kwessie van die eenheid van die wetenskap. Tot sover was daar talle metafisiese teorieë hieromtrent, soos die positivistiese, idealistiese en religieuse. In die meeste gevalle het dit neergekom op ' $n$ ongeoorloofde verabsolutering van een of ander aspek van die syn. Dreyer het die hele problematiek weg van die metafisika na die antropologie verskuif. Hierin alleen, meen hy, kan die eenheid gevind word: Wetenskap is die werk van die mens en is nooit onafhanklik van menslike aktiwiteit nie. Die wye verskeidenheid van die wetenskappe is die resultaat van die onuitputbare verskeidenheid van die vorme en moontlikhede van die menslike wêreld, terwyl die mens self gedifferensieerd is in sy verhoudinge tot sy wêreld en sy ideale. Eenheid is geleë in die feit dat wetenskap deel is van die menslike wêreld, deel van menslike aktiwiteit en dus deel van betekenisvolle totaliteit van 
menslike bestaan. Hierdie insigte het Dreyer reeds in sy professorale intreerede aan die Universiteit van Pretoria op 9 Junie 1970 laat blyk.

Dreyer het ' $n$ belangrike bydrae gelewer in die kwessie van die verhouding wetenskap-onwetenskap-nie-wetenskap. Sy besinning oor die grondslae van die wetenskap asook kriteria van wetenskaplikheid was goed gedoen en dit het wye weerklank gevind. In die toentertydse debat oor Christelike wetenskap al dan nie, het hy 'n leidende rol gespeel. Dit het veral na vore gekom in sy duidelike onderskeid tussen lewensopvatting en wetenskap by werke soos 'Buitewetenskaplike faktore in ons wetenskaplike besinning' (1963) en 'Die moontlikheid van filosofiese kommunikasie' (1963).

As deel van 'n departementele projek het Dreyer Die wysbegeerte van die Grieke die lig laat sien. Hierdie publikasie kan as een van sy groot werke beskou word. Hy het vir baie jare 'n belangstelling en entoesiasme vir die Grieke gehad. Dit het uitgeloop op 'n deeglike kennis en insig in die Griekse wysbegeerte. As mens in ag neem dat die Grieke die bakermat is van die wysbegeerte as sodanig, dan is dit begryplik watter belangrike bydrae hierdie werk is. Te meer omdat hy daarin geslaag het om op sy eie besondere manier in te sny na die wese van Griekse denkers en dit krities te ontleed. Dit ly geen twyfel nie dat hierdie werk en sy aandag aan die Grieke as sodanig tydens onder andere lesings en gesprekke, nog baie lank van veel betekenis vir wysgere sal wees.

\section{TWEE MYLPALE IN DIE WETENSKAP}

Hier word doelbewus gepraat van 'die' wetenskap en nie in die wetenskapsbeoefening van Dreyer alleen nie. Die rede is dat die genoemde twee mylpale inderdaad twee mylpale is in die hele corpus van die wetenskap. Hoekom?

Dit gebeur van tyd tot tyd dat 'n mens dikwels verneem van deurbrake, ontdekkings of uitvindings in een of ander wetenskap. Dis gewoonlik by die empiriese wetenskappe of sogenaamde feitewetenskappe. In sulke gevalle word daar ook gewag gemaak van die 'vooruitgang' van die wetenskap, omdat daar tot nuwe insigte en wendinge gekom is. Dit gebeur uiteraard nie sommer nie en dit vereis veel inset, toewyding en arbeid. Dit getuig ook van die hoë gehalte en genialiteit van die wetenskaplike. Hoewel wetenskappe soos die wysbegeerte en teologie in sekere opsigte anders te werk gaan as die 
empiriese wetenskappe, gebeur sodanige belangrike insigte en wendinge ook hier. Omdat dit nie empiriese wetenskappe is wat met eksperimentele waarneming werk nie, kom sulke gebeure miskien minder voor, maar is daarom soveel meer uitstaande in die betrokke wetenskap. 'n Mens sou kon stel dat PS Dreyer een van die min is wat in die wysbegeerte sodanige bakens opgerig het. Hoewel daar ' $n$ hele aantal mylpale aangedui kan word, soos geblyk het uit die vorige hoofstuk, is dit veral twee wat ons wil uitsonder, omdat die ingrypendheid en betekenisvolheid daarvan so uitstaande is.

Die eerste baken lê op die gebied van die waarheidsnorm by die geesteswetenskappe met spesiale verwysing na die geskiedenis.

Daar is die afgelope aantal dekades baie geworstel oor die probleem van die waarheidsnorm, veral met betrekking tot die korrespondensieen koherensieteorie. Baie wetenskaplikes het een of ander variasie van hierdie twee teorieë aangehang. Daar was ook ander, maar hierdie twee was en word dikwels as vanselfsprekend aanvaar. Dreyer het die korrespondensieteorie deurdringend ondersoek deur te kyk na sy basiese aanname dat 'n oordeel waar is as dit ooreenkom met die werklikheid waarop dit slaan. Hy het probleme aangesny veral met betrekking tot verwysing na dit waarmee ooreengestem sou word en tot die vraag wat die aard van die wetenskap is. Hy het tot die gevolgtrekking gekom dat hierdie teorie wel 'n element van die waarheid het, maar is as sodanig nie verdedigbaar nie.

Dan pak hy die koherensieteorie: Hier is die norm van die waarheid geleë in die samehang van een oordeel met ander oordele. Sy analise van die verskil tussen steekhoudendheid en koherensie alhier, verdien besondere vermelding. Ten gunste van die koherensieteorie meen Dreyer dat dit so is dat oordele in die wetenskap nie net van sy eie inhoud afhang nie, maar ook van die geheel waarin dit staan. Geen gebeure is heeltemal isoleerbaar nie, maar staan in samehang met ander. Feite is self die resultaat van 'n lang koherente werksaamheid. Tog konkludeer hy dat die koherensieteorie in sy geheel onvoldoende is: Reële wetenskappe is geen geslote sisteme nie; hulle dra hul waarheid nie in hulleself nie; hulle oordele het die wesenskenmerk van intensionaliteit en is voorwerplik gerig; dit mik op iets wat buite die oordeel en die wetenskap gerig is. Hier kom Dreyer tot insigte wat vir die geesteswetenskappe belanghebbend is.

As sowel die korrespondensie- en koherensieteorieë nie te handhaaf is nie, watter waarheidskriterium sou dan wel geldig wees? Deur hierdie vraag en probleem met sy eie antwoord op te los, rig Dreyer ' $n$ 
belangrike baken of mylpaal op: Hy stel sinvolheid as waarheidskriterium.

Hierdie kriterium hou in dat die geesteswetenskappe die werklikheid so moet tematiseer dat die mens waarmee hulle werk, konkreet teenwoordig is in die wêreld. Laasgenoemde is altyd ' $n$ totaliteit van konkrete dinge en ook van waardes, norme, idees en medemense wat onlosmaaklik deel is van ons menswees. As lyflike persoon is menswees wesenlik vervul met en uitdrukking van betekenis of sin. Die mens is bewustelik nie 'n gevangene van sy eie bewussyn nie, maar is steeds oor hom heen gerig, byvoorbeeld met en in sy leefwèreld. Sy liggaamshouding, elke gebaar van sy hande, elke beweging van sy gesig, oë en mond, elke geluid wat hy uiter, is betekenisgewing aan sy verhouding met sy leefwêreld. By uitstek en heel besonderlik is dit om op betekenisvolle wyse in kommunikasie te tree met sy medemens. Eweneens is dit die geval by die kengebeure van die geesteswetenskappe: Dié wetenskappe werk primêr nie in terme van koherensie en korrespondensie nie, maar deur betekenisvol in kommunikasie te tree. Dit beteken dat hulle die mens nie as louter objek ken nie, maar as die betekenisvolle teenwoordigheid van ' $n$ medemens.

Gevolglik meen Dreyer dat 'n hermeneutiese ken van die mens slegs na analogie van jouself onvoldoende is. ' $n$ Voldoende kenning sou wees 'n verstaan van die mens soos wat hy is, dit wil sê soos wat hy jou tegemoettree en ontmoet. Die wetenskaplike moet wel as kensubjek sy inset maak. Dan het ons egter nie met 'n subjek te doen wat 'n objek ken nie, maar is dit twee subjekte wat mekaar ontmoet, met mekaar omgaan en elkeen die ander in sy eie betekenisvolheid verstaan: Die een mens verstaan die ander op grond van ons intersubjektiwiteit, ons met-mekaar-wees, ons ontmoeting met mekaar, ons saamvoel met mekaar. In die ontmoeting het alles van die ander vir my betekenis. Dan ken jy hom nie soos ek is nie, maar soos hy is.

Die waarheidsnorm is dus sinvolheid. Die wetenskap se spreke oor die mens is sinvol. As so uitdrukking gegee word aan wat die mens werklik is, dit wil sê die mens tereg laat kom as lewende, lyflike persoon, kom die volheid van betekenis na vore.

Waar en hoe weet die wetenskaplike dit? Dit sal hy weet as hy die mens se leefwêreld tematiseer in sy ondersoeke. Menslike bestaan is sinvolle bestaan, omdat die mens gedurig besig is om vormend en gestaltegewend met sy leefwêreld om te gaan. Die wetenskaplike ken dus nie sinvolheid toe nie. Dit kom nie bevat 'agterna' nie. Sy taak is om die wesenlike sinvolheid van die aard van menslike bestaan tot 
spreke te bring. Metodologies kom dit neer op die geniale, intuitiewe gryp van die sinvolheid van menswees. Dit is moontlik vanweë intersubjektiewe kommunikasie tussen mense. Dis moontlik omdat die mens geen dinglike objek is nie, maar altyd medesubjek is wat besig is om betekenisvol gestalte te gee aan homself en sy leefwêreld. Omdat hy aldus as medesubjek vir ons verstaanbaar is, is dit moontlik om die mens op so ' $n$ wyse te beskrywe dat ons beskrywing sinvol is. Dit laat reg geskied aan die mens as mens.

In hierdie konstruksies van Dreyer, merk ons dat hy hermeneutiesfenomenologies redeneer. Sy denke is hier gevorm deur Edmund Husserl, Martin Heidegger, Emilio Betti, en andere. Met hierdie denke kan PS Dreyer se naam te staan kom langs die grotes.

'n Tweede mylpaal of baken plaas Dreyer op die gebied van die etiek. Hy toon groot insig in talle sedelerige strome en etiese fenomene, asook die huidige stand van etiek wat hom baie geïnteresseer het, soos blyk uit sy Hoofstrome van die Sedeleer en sy referaat gelewer tydens sy jubileumviering as dosent aan die Universiteit van Pretoria.

In die area van die ken van waardes, het Dreyer daarstellings gemaak wat seer sekerlik van blywende betekenis sal wees. Tot sover was daar in die etiek en waardefilosofie drie standpunte: Waardes kan geken word deur die gevoel of emosies, deur die rede of intellek en laastens deur die wil. Hieroor het Dreyer veel denkarbeid gedoen. Die eerste standpunt dat waardes in die voelakte gewaar word, soos wat ons kleure in die sienakte waarneem, sowel as die tweede standpunt dat kenning van waardes neerkom op 'n predikaat wat jy rasioneel aan 'n objek heg, kan nie gehandhaaf word nie. Die derde standpunt ten opsigte van die wil, hou meer in, maar is onvoldoende. Dis ' $n$ driedeling wat teruggaan na die Griekse denke.

Hierteenoor het Dreyer gekom met 'n nuwe en vierde standpunt wat nie net die probleme van die vorige drie ondervang nie, maar as sodanig ' $n$ treffende aanpak konstitueer. Teenoor, maar te midde van die vorige drie, stel Dreyer waardering. Waardering is ' $n$ akte wat net so reëel, oorspronklik en fundamenteel is as die ander drie. Teenoor die denke is waardering irrasioneel - wat jy as mooi vind, is nie ' $n$ rasionele akte nie, maar ' $n$ akte van waardering. Dit is onmiddellik en nie diskursief nie. Andersyds staan waardering weer teenoor gevoel. Gevoel of emosie meen Dreyer is ' $n$ ongewilde reaksie, terwyl waardering juis 'n gewilde daad is. Gevoel verloop meganies, word gewek of is verbind aan iets, terwyl waardering bewustelik op iets gerig word, dit 
wil sê dis intensioneel. Gevoel het niks te doen met waardes en norme nie, terwyl waardering wel dienooreenkomstig geskied.

Waardering is derhalwe verwant aan denke, omdat dit bewus intensioneel is. Dis verwant aan gevoel, deurdat dit nie tot ons rasioneel herlei kan word nie. Waardering is nie ons denke nie, maar dit gebruik wel die denke. Waardering is nie gevoel nie, maar dit kan sterk gevoelens opwek. Dit is ook nie wil nie, maar dit kan ons wek tot wilsinspanning.

Waardes benader ons nie net subjektief nie, maar hulle is ook objektief daar. Objekte (materieel of ideëel) is draers van waarde. Tog is dit nie identies met waardes nie. Insgelyks is waarde en syn nie dieselfde nie. Waardes is wel objek-betrokke, synsgemoeid. Tog is hulle werklikheid nie afhanklik van hul verwerkliking 'in die syn' nie. Waardes is subjekbetrokke, maar het nie hul oorsprong in die subjek nie.

Dit is duidelik dat Dreyer se arbeid nog baie lank betekenisvol sal wees. Hy het bakens opgerig wat staan langs die pad van die Wysbegeerte en waarlangs altyd verbygereis sal word.

\section{PUBLIKASIES}

1. Geboorte - Huwelik-Dood 1955. Krugersdorp: NHW-Pers. Hersiene en vermeerderde uitgawe 1985 . 120 bladsye.

2. Brandwagte van God: ' $n$ Handleiding vir ouderlinge 1956. Krugersdorp: NHW-Pers. (Twee keer herdruk.) 91 bladsye.

3. Inleiding in die filosofie van die geskiedenis 1974. Kaapstad: HAUM. 259 bladsye.

4. Die wysbegeerte van die Grieke 1975. Pretoria: HAUM. Tweede druk 1981. 155 bladsye.

5. Afrikaner-Liberalisme (redakteur en medewerker) 1977. Pretoria: Boekenhout. 112 bladsye.

6. Rewolusie en terreur 1978. Pretoria: Boekenhout. 124 bladsye.

7. Vroue as predikante 1977. Pretoria: HAUM. 59 bladsye.

8. Die wankelende rots: ' $n$ Lewensgeskiedenis van die apostel Petrus 1979. Kaapstad: HAUM. 133 bladsye.

9. Hoofstrominge van Sedeleer 1979. Pretoria: HAUM. 138 bladsye.

10. Dienspligweiering 1980. Pretoria: HAUM. 29 bladsye.

11. Laat my lammers wei (Preekbundel) 1981. Tweede druk. Pretoria: HAUM. 61 bladsye.

12. Verhandeling en proefskrifte is uitgelaat. 


\section{ARTIKELS}

1. Die geestesstruktuur van die ongeloof. HTS $7 / 2$ en 3 (1951).

2. Die problematiek van die geesteswetenskappe. HTS 8/4 (1952).

3. Die godsdienskritiek van Ludwig Feuerbach en Karl Marx. HTS 11/1 (1954).

4. Oorspronklikheid en vryheid. HTS 13/1 (1957).

5. Historisme en Christendom. HTS 14/1 (1958).

6. Die ontwerp van ' $n$ sendingbeleid in die huidige situasie. HTS $15 / 2-4$ (1959).

7. Die geskiedkundige en die geskiedenis. HTS 18/4 (1958).

8. Teosofie. HTS 20/2 (1965).

9. Bo-natuurlike wesens en godsdienstige feeste by die Zulu. HTS 21/4 (1965).

10. Hoofprobleme van die filosofie en die teologie van die Geskiedenis. HTS 22/4 (1966).

11. Buite-wetenskaplike faktore in ons wetenskaplike besinning. Tydskrif vir Geesteswetenskappe $3 / 3$ (1963).

12. Die moontlikheid van fislosofiese kommunikasie. Tydskrif vir Geesteswetenskappe 3/3 (1963).

13. Die probleme van die sin van die geskiedenis. Tydskrif vir Geesteswetenskappe 6/2 (1966).

14. Enkele aspekte van die geskiedskrywing van Arnold J Toynbee. Historia 3/1.

15. Die grondslae van die Westerse leefwyse, in Cronjé, G (red) 1963 , Die Westerse kultuur in Suid-Afrika. Pretoria: Van Schaik.

16. Van mite tot wetenskap, in Cronjé, G (red) 1966, Kultuurbeinvloeding in die oudheid. Pretoria: Van Schaik. (Fakulteitslesings).

17. Die wysgerige Antropologie en die Teologie, in Cronjé, G (red) 1966, Die wysgerige Antropologie en die Menswetenskappe. Pretoria: Van Schaik. (Fakulteitslesings).

18. Die wysgerige Antropologie en die Geskiedenis, in Cronjé, G. (red.) 1966, Die wysgerige Antropologie en die Menswetenskappe. Pretoria: Van Schaik. (Fakulteitslesings).

19. 'n Tipering van Afrikanerskap, in Nel, PG (red) 1979, Die Kultuurontplooiing van die Afrikaner. Pretoria: HAUM. (Fakulteitslesings).

20. Die objek en metode van die Geesteswetenskappe, in Dreyer, PS (red) 1983, Objek en metode in die Geestewetenskappe. Pretoria: Universiteit van Pretoria. (Fakulteitslesings).

21. Die filosofiese grondslae van die Kommunisme, in Cronjé, $G$ (red) 1969, Kommunisme: Teorie en praktyk. Pretoria: Van Schaik. 
22. Die voor-Platoniese staatsbeskouings, in Faure, AM et al (red) 1981, Die Westerse politieke tradisie. Pretoria: Academica.

23. Plato (427-347 v C), in Faure, AM et al (red) 1981, Die Westerse politieke tradisie. Pretoria: Academica.

24. Aristoteles (384-322 v C), in Faure, AM et al (red) 1981, Die Westerse politieke tradisie. Pretoria: Academica.

25. Die etiek van navorsing op mense. Geneeskunde 16/3 (1974).

26. Gedragskodes. Municipal Administration and Engineering 36/421 (1970).

27. Gedragskodes as probleem. Municipal Administration and Engineering 36/432 (1971).

28. Die eenheid van die wetenskappe 1971. (Publikasies van die Universiteit van Pretoria, Nuwe Reeks nr 69). Pretoria: Universiteit van Pretoria. (Intreerede).

29. Die Ned Herv Kerk en die sending 1957. Uitgegee deur die Ring van Pretoria. (30 bladsye).

30. Filosofie en Geskiedenis. Historia 29/2 (1981).

31. Die noodsaak en essensie van akademiese arbeid, in Die uitdaging aan die moderne universiteit 1977. (Seminare en Simposia B 3). Port Elizabeth: Universiteit van Port Elizabeth.

32. The meaning of history: Probing the problem, in König, A \& Keane, H (ed) 1980, The meaning of history. Pretoria: University of South Africa.

33. Enkele opmerkings oor objek en tyd in die geskiedskrywing, in Die kerk in die wêreld: ' $n$ Bundel opstelle aangebied aan prof dr AD Pont by sy 25-jarige ampsjubileum 1982. Pretoria: HAUM.

34. Immigrant en kultuur, in Immigrasie en immigrante-inburgering 1977. Referate gelewer by die Derde Nasionale Kongres, 26 en 27 Oktober 1977, Pretoria.

35. Hedendaagse vryheidsideologieë in die Akrikaanse situasie, in Nel, PG (red) 1981, Afrikanerkultuur: Fondament en vergesig. Pretoria: Universiteit van Pretoria. (Fakulteitslesings).

36. Die aard en taakstelling van die universiteit, in Nel, PG (red) 1982, Die Universiteit: Verlede, hede en toekoms. Roodepoort: CUM-boeke. (Fakulteitslesings).

37. Vrae 1-8 van die Heidelbergse Kategismus, in Dreyer, PS, Koekemoer, JH \& van Wyk, DJC 1983, So glo ons. Pretoria: Kital. 


\section{OPGETREE AS REDAKTEUR}

1. Homo Viator: Feesbundel aangebied aan prof $C K$ Oberholzer s a. Kaapstad: HAUM.

2. Permanence and change: Lectures on the philosophy of history, by prof Karl Löwith 1969. Cape Town: HAUM.

\section{BELANGRIKSTE RADE EN ADVIESKOMMISSIES}

1. Lid van die Sendingraad van die Nederduitsch Hervormde Kerk, in 1952, kort daarna voorsitter geword en is dit nog steeds.

2. Ouderling, Pretoria-Oos-gemeente, sedert 1954.

3. Lid van die Kommissie van die Algemene Kerkvergadering van die Nederduitsch Hervormde Kerk, sedert 1955.

4. Lid van die redaksie van Hervormde Teologiese Studies, sedert 1953.

5. Lid van die redaksie van Die Hervormer, vir baie jare.

6. Redakteur van die Almanak, sedert 1977.

7. Volle lid van die Suid-Afrikaanse Akademie vir Wetenskap en Kuns.

8. Een van die eerste Raadslede van die Universiteit van Zoeloeland, en het dit vir 21 jaar gebly.

9. Lid van die Uitvoerende Komitee van die Raad vir Wetenskaplike Publikasies. 